\title{
PROYECTO DE ESTUDIO Y DOCUMENTACIÓN DE LOS RESTOS DE LA GUERRA CIVIL ESPAÑOLA EN EL TÉRMINO MUNICIPAL DE PINTO, MADRID
}

\author{
Ángela Crespo Fraguas y Miguel Ángel Díaz Moreno
}

\section{Resumen:}

Durante los primeros meses del año 2014 se llevaron a cabo diferentes labores encaminadas a la localización y documentación de los vestigios de la Guerra Civil en el término municipal de Pinto (Madrid), que contaron con el aval administrativo de la Concejalía de Cultura del Ayuntamiento de dicha localidad.

Se realizó una prospección arqueológica que tuvo como resultado la localización de restos en los parajes de Los Yesares, el cerro Cabeza Fuerte, el Puerto de las dos Caras, Valdecantos, Valdegrima y Valdeciervos, todos ellos situados en la zona noreste y este del término municipal e incluidos en un paisaje singular como es el Parque Regional del Sureste de la Comunidad de Madrid. Todas las zonas están relacionadas con las operaciones militares que tuvieron lugar en torno a Madrid durante la primera fase de la Batalla del Jarama en febrero de 1937, tras la cual se fortificaron los lugares mencionados que han sido objeto de estudio.

\section{Palabras clave:}

Guerra Civil, fortificaciones, Pinto, Parque Regional del Sureste, prospección.

\section{Abstrac:}

During the early months of 2014 a several Works have been carried on to locate and document arcaheological remains of the Spanish Civil War (1936-1939) in the municipality of Pinto (Madrid), supported by the local Culture Department of the Council.

As a result of the archaeological survey, several sites of this period were recorded-Los Yesates, Cabeza Fuerte Hill, Puerto de las dos Caras, Valdecantos, Valdegrima and Valdeciervos- all of them located at the east or north-eastern areas of the municipality and within the Southeast Regional Park of Madrid. All these sites are related to the military operations around Madrid which took place in February 1937 during the first phase of the Battle of the Jarama, after which the aforementioned sites were fortified.

\section{Key words:}

Spanish Civil War, fortifications, Pinto, Southeast Regional Park, survey.

1 Equipo de Cota 667 - Arqueología y Patrimonio - pintocota667@gmail.com 


\section{Introducción}

Fruto de la iniciativa particular y del interés personal de los autores de este trabajo fue posible la realización del estudio de los restos de la Guerra Civil Española (1936-1939) en el municipio de Pinto (Madrid).

Con el apoyo institucional de la Concejalía de Cultura del Ayuntamiento de ésta localidad se obtuvieron los permisos necesarios otorgados por la Dirección General de Patrimonio Histórico de la Comunidad de Madrid, y tras la realización de los pertinentes trámites administrativos comenzamos a desarrollar la fase de trabajo en campo, que consistió principalmente en tareas de prospección y documentación de estructuras, cuya metodología y resultados serán expuestos más adelante.

Todas las labores de campo se realizaron durante el año 2014, pero no de forma continuada, ya que se tuvo en cuenta la accesibilidad a los terrenos objeto de estudio, que se veía afectada por factores como la meteorología, labores agrícolas o periodos de parada biológica para cría de especies autóctonas.

Tras una primera aproximación a los hechos históricos se determinaron las aéreas de trabajo, que se localizaban principalmente en la zona noreste del municipio, las cuales se prospectaron, documentándose en ellas estructuras en diversos parajes relacionadas con los momentos iniciales de la Batalla del Jarama en febrero de 1937.

Para entender por qué estos restos han llegado hasta nuestros días y la razón de su ubicación, es necesario conocer como se desarrollaron los acontecimientos y que aspectos relacionados con el medio físico influyeron para su construcción en su momento y para su posterior conservación.

\section{Contextualización histórica}

Tras el golpe de estado del 18 de Julio de 1936 tanto el gobierno republicano como los militares sublevados confiaron demasiado en sus posibilidades de éxito, lo que influyo negativamente en la recién creada situación. Por un lado, la respuesta de las autoridades republicanas no fue efectiva, pues confiaron demasiado en la posibilidad de acabar rápidamente con el alzamiento. Por su parte, los generales sublevados creían que, a pesar de no haber tenido el éxito inicial que esperaban, con la ocupación de Madrid podrían concluir rápidamente con el conflicto y hacerse con el poder. Según Beevor los sublevados se habían propuesto tomar Madrid el 12 de octubre "día de la raza" ${ }^{2}$. Ese exceso de confianza influyó en que la recién iniciada guerra se prolongase durante los tres años que siguieron.

2 A. BEEVOR: La Guerra Civil Española. Círculo de Lectores, Barcelona: 2005, 252. 
En Sevilla se organizó la denominada "Columna Madrid" al mando del General Varela, que partió el 3 de agosto hacia la capital. En su avance durante el verano de 1936 tuvieron lugar importantes episodios de la contienda, como la ocupación de Badajoz (14 de agosto), la de Talavera de la Reina (3 de septiembre) y la de Toledo, con el episodio del fin del asedio de Alcázar (27 de septiembre). Esta última plaza sería la base de partida de las tres columnas dirigidas por Varela y comandadas por los coroneles Yagüe, Barrón y Monasterio, que a principios de octubre iniciaron el asalto de la capital siguiendo los ejes de las carreteras de Extremadura, Toledo y Andalucía respectivamente, en lo que sería el germen de lo que se conoce como la "Batalla de Madrid".

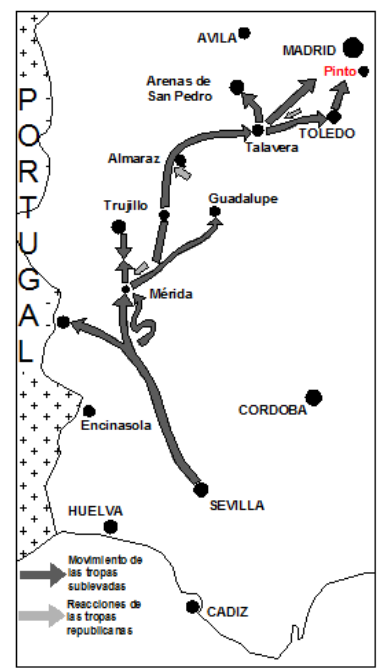

Fig. 1. Avance de la "columna Madrid". Elaboración de los autores a partir de H.Thomas.1985. H.THOMAS: “La Guerra Civil Española”. Vol. 3, 4 y 6. Urbión, Madrid: 1985.

En estos primeros momentos el avance de las tropas golpistas había sido rápido debido a la desintegración del ejército en el bando republicano y a la mala actuación de las milicias populares. Pero esta situación cambió en octubre de 1936 al crearse el "Ejército Popular de la Republica", que combinó a las milicias populares con las unidades del ejército regular que permanecieron fieles al gobierno.

Tras la ocupación de los pueblos del norte de la provincia de Toledo, en noviembre de 1936 se comenzó a combatir en los alrededores de la capital. El dos de noviembre los sublevados ya habían ocupado Villaviciosa de Odón, Móstoles, Fuenlabrada y Pinto.

Temiendo la inminente caída de la capital el Gobierno de Largo Caballero, en una decisión inesperada, se trasladó a Valencia el día 6 de noviembre. El General 
Miaja se quedó al mando de la Junta de Defensa de Madrid nombrando como jefe de Estado Mayor al Teniente Coronel de infantería, Vicente Rojo. ${ }^{3}$

Durante todo el mes de noviembre de 1936 se combatió duramente en un sector que abarcaba desde Ciudad Universitaria por el norte hasta la carretera de Andalucía, a la altura del barrio de Usera, por el sur.

Ante la defensa republicana de este sector y la imposibilidad de los sublevados de seguir avanzando, Franco ordenó el 23 de noviembre cesar los ataques y fortificar las posiciones para estabilizar el frente. ${ }^{4}$

Este hecho no supuso la renuncia a tomar la capital, sino que se produjo un cambio de estrategia que daría lugar en los próximos meses, ya en el año 1937, a varias ofensivas por parte de ambos bandos, encaminadas a tomar la ciudad en un caso y a aliviar el cerco en el caso contrario. En el marco de esta estrategia acaecieron las batallas del Jarama, Guadalajara y Brunete durante los meses de febrero, marzo y julio de 1937 respectivamente.

A mediados de enero de 1937 ambos bandos eran conscientes de la importancia estratégica que tenía la carretera de Madrid-Valencia, pues había quedado como importante corredor por el que Ilegaban suministros a la capital. Por ello, los dos bandos habían estado acumulando tropas y realizando "movimientos de líneas" ${ }^{5}$ en la zona para ser los primeros en iniciar la ofensiva, En este sentido se entienden los combates acaecidos en el Cerro de los Ángeles, en Getafe, o el primer intento de ocupación del cerro Cabeza Fuerte, en Pinto, que terminó con la vuelta a las posiciones de partida en el citado municipio de las tropas franquistas debido a las fuertes Iluvias que hicieron impracticable el terreno. ${ }^{6}$

Los planes de ataque se ralentizaron pero siguieron ejecutándose y para ello el ejército no gubernamental acantonó cinco brigadas en el eje Norte-Sur que constituía la carretera de Andalucía, en los pueblos de Pinto y Valdemoro, al mando del general Varela, que iniciarían su avance el día 6 de febrero, dando comienzo lo que se conocería en adelante como "Batalla del Jarama". Desde Valdemoro partieron las brigadas de los coroneles Asensio y García-Escámez, mientras que desde Pinto partieron las de los coroneles Rada y Sáez de Buruaga, quedando la de Barrón en reserva, que apoyaría más adelante al par anterior.

3 J. GONZÁLEZ DE MIGUEL: "La defensa de Madrid". Desperta Ferro Contemporánea, 4 (2014), 28-39.

4 E. GONZÁLEZ PONS: "La Batalla de Madrid". Ejercito revista ilustrada de las armas y servicios, 12 (1941), 35.

5 Pequeños ataques cuya finalidad es obtener avances sobre el terreno para posicionarse de forma ventajosa en futuras operaciones de mayor relevancia.

6 J.M. GARCÍA RAMIREZ: La Batalla del Jarama Febrero 1937. Almena, Madrid: 2007. 


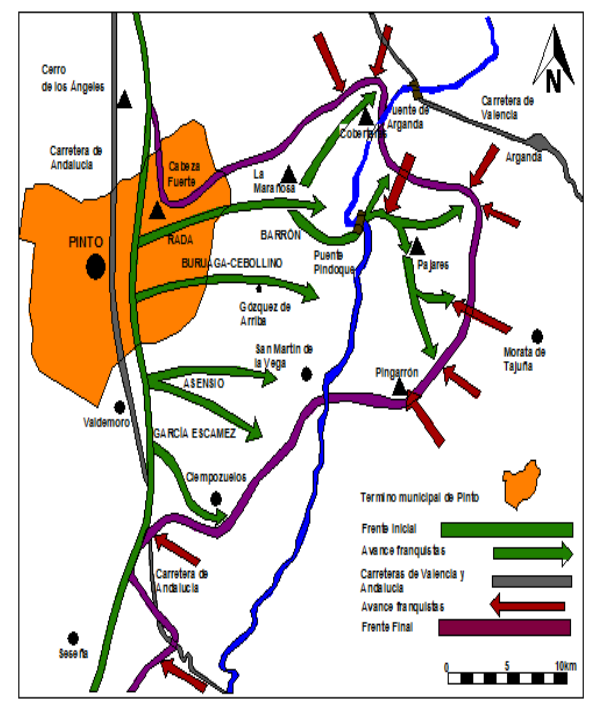

Fig. 2. Mapa esquemático de la Batalla del Jarama. Elaboración de los autores a partir de H.Thomas.1985.

El coronel Rada fue el primero en iniciar el avance en dirección noreste ocupando los vértices que se extienden desde la carretera de Andalucía hasta la unión de los ríos Manzanares y Jarama. Estas alturas son, de suroeste a noreste: Los Yesares, Cabeza Fuerte, Cota 649, todas en Pinto y Monte del Fraile, La Marañosa y Coberteras en San Martín de la Vega. En su avance se enfrentó a las tropas de la 48 Brigada Mixta al mando del coronel Jiménez Orge, que defendía el sector de Perales a Pinto. La I Brigada de Rada tenía por misión proteger el flanco Norte de la ofensiva franquista ante cualquier respuesta republicana que viniese desde el sur de la capital para que las demás brigadas pudiesen operar en la zona central. En este sentido, el coronel Sáez de Buruaga comenzó su avance igualmente desde Pinto en dirección este con la intención de ocupar San Martín de la Vega, ya a las orillas del río Jarama. Avanzaría por una zona en la que terminaba el sector defendido por la 48 Brigada Mixta y comenzaba el sector asignado a la 23 Brigada Mixta, al mando del teniente coronel Camilo Sicilia, que defendía el sector entre Gózquez de Arriba y las estribaciones de Ciempozuelos, zona asignada a la 18 Brigada Mixta. A la vanguardia de la II Brigada de Sáez de Buruaga avanzó la caballería del teniente coronel Cebollino por el camino de Valdeciervos, que discurre entre el término municipal de Pinto y Gózquez de Arriba. Del mismo modo, la artillería de acompañamiento avanzó sus posiciones desde la loma Valdeciervos (Pinto) a la casa del Platero (junto a Gózquez).

Como se puede apreciar, es esta primera fase de la Batalla del Jarama la que protagonizan las posiciones localizadas en Pinto objeto de nuestro trabajo. Entre marzo de 1937 y mayo de 1938 se desplegó la División 12 para cubrir el sector 
entre Getafe y San Martín de la Vega, que sería sustituida posteriormente por los efectivos de la División 18, que quedaría al cargo de este sector entre mayo de 1938 y el final de la guerra en abril de $1939 .^{7}$

Ambas unidades continuaron de forma más intensiva las labores de fortificación iniciadas de modo precipitado durante el desarrollo de las operaciones. Los trabajos de fortificación tenían por objeto proteger las zonas conquistadas de posibles contrataques enemigos y así estabilizar el frente, de modo que fuese posible guarnecerlo con pequeños contingentes de tropas para así destinar más efectivos a zonas con operaciones en marcha.

Estos trabajos consistían en la ampliación y mejora de la red de trincheras de cada posición que había empezado a construirse durante el desarrollo de la Batalla del Jarama. Del mismo modo, se levantaron fortines en hormigón, abrigos para la tropa y otras estructuras que se comentarán en el siguiente apartado, y que conforman la evidencia arqueológica que ha llegado hasta nuestros días.

\section{El medio físico}

En estas líneas explicaremos de forma muy breve el marco geológico y medioambiental en el que se localizan los restos de la Guerra Civil documentados en Pinto. Este es un aspecto de especial importancia ya que la elección de los lugares en su momento para su construcción estuvo obviamente condicionados por el terreno, y junto a esto, el hecho de encontrarse localizados en una zona protegida como es el Parque Regional del Sureste de la Comunidad de Madrid ha influido de manera decisiva en su conservación, y ha permitido que llegaran hasta nuestros días.

Como ya hemos comentado, la zona en la que se ubican las estructuras militares de la Guerra Civil se localiza en el sector noreste del término municipal de Pinto. Esta zona está incluida en la denominada Cuenca de Madrid, también llamada "Cuenca del Tajo" ${ }^{8}$. El sustrato de la zona más céntrica de la Comunidad de Madrid está compuesto por arcosas y conglomerados. Particularmente, en el tercio sureste de Madrid destacan los yesos, calizas, arcillas y limos. Este aspecto es muy relevante, ya que es en estas elevaciones de sustrato calizo en las que se localizan las estructuras de la Guerra Civil. Otro aspecto importante que ya hemos señalado es que las zonas en las que se han llevado a cabo las labores de prospección y documentación en el término municipal de Pinto, se encuentran localizadas dentro del Parque Regional del Sureste de la Comunidad de Madrid.

7 R. CATELLANO: Los restos del asedio. Fortificaciones de la Guerra Civil en el Frente de Madrid Ejército Nacional. Almena, Madrid: 2004.

8 F. ALFÉREZ: "Estudio del sistema de terrazas del rio Tajo al oeste de Toledo". Estudios GeológiCos, 33 (1977), 223-250. 
Este espacio se articula en torno a los cursos bajos de los ríos Manzanares y Jarama, que, pese a su nivel de protección, se trata de un espacio que está muy amenazado y continuamente afectado por los grandes núcleos de población que se encuentran en sus alrededores, lo que ha propiciado que tenga su propio ordenamiento jurídico en cuanto a la protección del mismo.

Por ultimo quisiéramos señalar que de no ser por las repoblaciones con pino o la existencia en algunas zonas de explotaciones de áridos, así como la existencia de dos vertederos controlados, en esencia el paisaje que albergó los combates durante la Guerra Civil era muy similar al actual, con la salvedad del abandono en el que se encontrarían muchos campos de labor debido a la contienda.

\section{Metodología y resultados}

Los trabajos arqueológicos consistieron en la realización de una prospección intensiva y la documentación de las estructuras que se observaban en superficie. A pesar de que la ubicación de las estructuras de mayor entidad como fortines y trincheras era conocida de antemano, las áreas en las que se iba a trabajar eran mucho más amplias, por lo que, para determinar su extensión y la zona de actuación, junto con estudios de carácter historiográfico, fue de gran utilidad el estudio de fotografías aéreas de diferentes periodos que son el resultado de los diferentes vuelos que se han ido realizando sobre nuestro país desde mediados del siglo XX hasta la actualidad.

El uso de este tipo de material (junto a la cartografía tradicional histórica y actual) ayudó a planificar la prospección de modo racional, a la vez que en fases posteriores del estudio sirvió para determinar aspectos como la existencia en su día de estructuras de hormigón que habían sido destruidas en los primeros años de posguerra para despejar los campos de cultivo, la observación de tramos de trinchera igualmente desaparecidos o para realizar una comparativa de la red de caminería con la existente en la actualidad, lo que contrastado con documentos aportados por diferentes fuentes (archivos, publicaciones, testimonios...) ha hecho posible que la reconstrucción de los acontecimientos sea lo más cercana a la realidad. Junto a estos aspectos también es destacable la observación del "crecimiento diferencial", producido por la mayor densidad de vegetación en lugares dónde el terreno ha sido removido por estructuras antrópicas, lo que permite apreciar su planta o trazado aunque estas ya no se conserven.

Para la realización de las batidas de prospección se contó con la participación de colaboradores que provenían todos del ámbito universitario y arqueológico. Durante las mismas los materiales localizados en superficie eran etiquetados y georeferenciados mediante el uso de GPS. De este modo, con los datos obtenidos se generaron planos en un Sistema de Información Geográfica (SIG) que 
determinan la localización exacta del objeto y las zonas de distribución y dispersión de los mismos. Esto ha permitido que se conozca la procedencia exacta de las más de 1500 piezas localizadas en superficie, y ha hecho posible diferenciar zonas de actividad en función de la tipología de los restos localizados en las mismas. Así se han podido determinar con exactitud en las diferentes zonas que detallamos a continuación las áreas de hábitat, con abundancia de materiales relacionados con el avituallamiento de tropas y utensilios de la vida cotidiana, las áreas de almacenaje y pernoctación, con restos constructivos asociados a la realización de "abrigos", y las zonas de "primera línea" con restos bélicos relacionados con los combates.

En lo referente a las evidencias inmuebles que han llegado a nuestros días, estas se localizan en los parajes de Los Yesares, el cerro Cabeza Fuerte, el Puerto de las dos Caras/Valdecantos, Valdegrima y Valdeciervos. En todos ellos se han conservado estructuras negativas excavadas en el terreno (trincheras, abrigos y pozos de tirador entre otros elementos) y estructuras positivas construidas con hormigón armado que fueron realizadas una vez estabilizado el frente.

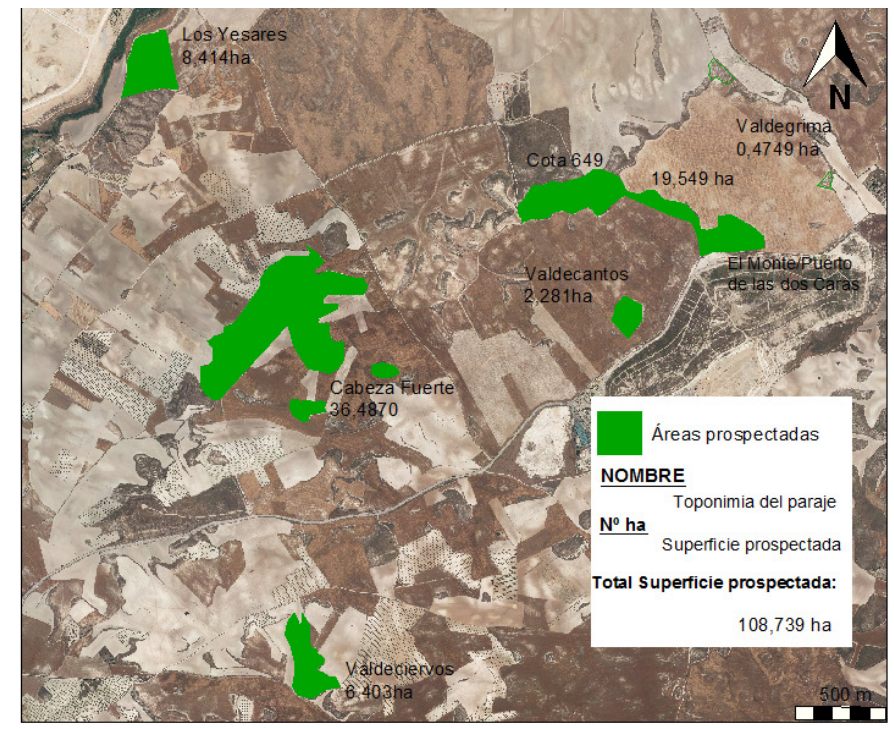

Fig. 3. Imagen de las zonas prospectadas con restos de la Guerra Civil en Pinto. Elaboración de los autores.

Si comenzamos el repaso de cada una de ellas desde el sur hacia el noreste, en primer lugar debemos mencionar la posición de Los Yesares, que se correspondería con la posición "Vega baja" en la época. Es una de las zonas mejor conservadas debido a que el sustrato en que se realizaron las estructuras excavadas es de roca de yeso, lo que ha permitido que lleguen a nuestros días en buen estado. 
En este lugar encontramos una red de trincheras con pozos de tirador, abrigos en las zonas desenfiladas, zanjas antitanque e incluso una pequeña cueva que haría las veces de refugio para oficiales.

Junto a estas estructuras negativas también se han documentado cuatro fortines mixtos (planta rectangular rematada en el frontal de forma ovalada) realizados con hormigón armado en un estado de conservación muy bueno.

En cuanto al material recuperado en esta zona durante las tareas de prospección, se ha recogido un conjunto de 139 objetos relacionado con la vida cotidiana en el frente y material bélico.

Entre el material de uso cotidiano destaca el hallazgo de numerosos fragmentos de cristal procedente de varios tinteros y de botellas de bebida, principalmente de la marca "Pedro Domecq", así como latas de conserva, si bien en ambos casos la presencia de estos elementos es escasa. También se han localizado dos botones posiblemente de uniformes, y varios fragmentos de alambre de espino procedente de la fortificación del lugar. Por lo que respecta al material bélico se han localizado varias vainas de fusil de procedencia española, alemana e italiana, aspecto este que subraya la adscripción de la posición. Junto a este material se ha documentado una tapa de caja de munición así como varios proyectiles ya disparados. Es interesante señalar que se ha recogido un conjunto de munición de pistola de $9 \mathrm{~mm}$ parabellum procedente de prácticas de tiro ilegales realizadas en nuestros días.

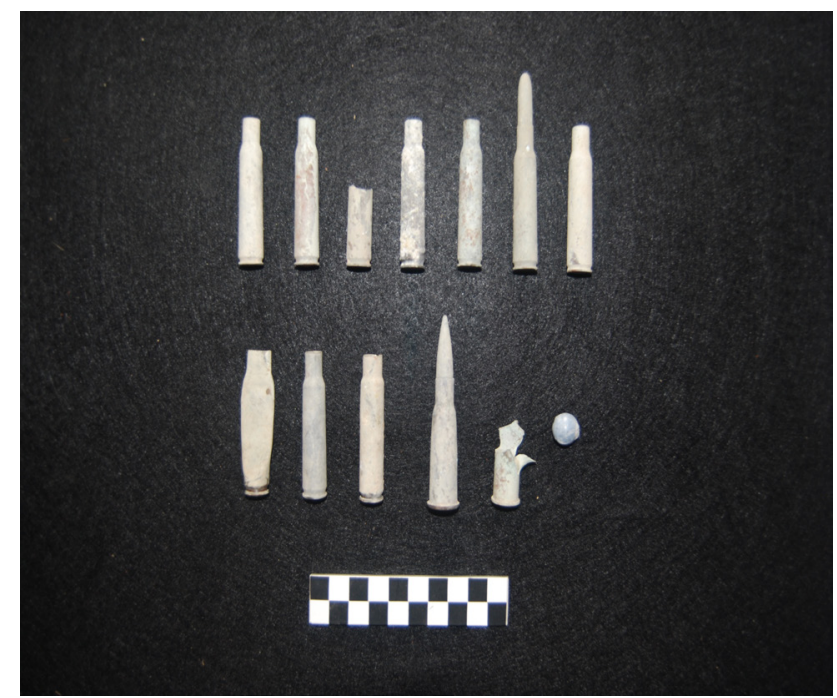

Fig. 4A. Ejemplo de munición encontrada en prospección. Fotografía de los autores.

El mismo esquema de fortificación se documenta en la siguiente posición, el cerro Cabeza Fuerte, conocido así en la época y siendo el paraje mas menciona- 
do en la bibliografía, pues es la cota más elevada de la zona. En él se documentan igualmente estructuras excavadas del mismo tipo (salvo el refugio) y otros cuatro fortines idénticos a los de la posición anterior, así como los restos de una pequeña caseta de ladrillo que pudo ser un puesto de mando. Los materiales hallados en esta posición constituyen el conjunto más numeroso de los localizados con una cantidad que se eleva a 991 objetos recuperados, que incluyen metales, cristal, cerámica, madera y cuero. Entre el conjunto de objetos metálicos destaca los numerosos restos de munición de varios calibres usados por ambos bandos, lo que se corresponde con las ocupaciones sucesivas del Cerro, así como restos de metralla procedentes de obuses variados y de granadas de mano. También hay que señalar el importante conjunto de objetos de uso cotidiano en el que destacan las numerosas latas de conserva de todo tipo, los restos de equipo individual (cantimplora, cuchara, objetos de aseo personal etc.). También es destacable el conjunto de piquetas y restos de alambre de espino procedente de la fortificación de la posición. Junto a este grupo de materiales aparece además numerosos fragmentos de cristal correspondientes a tinteros, botellas de anís, jerez y garrafas de vino, así como varios fragmentos de platos de loza, botijos y cantaros.

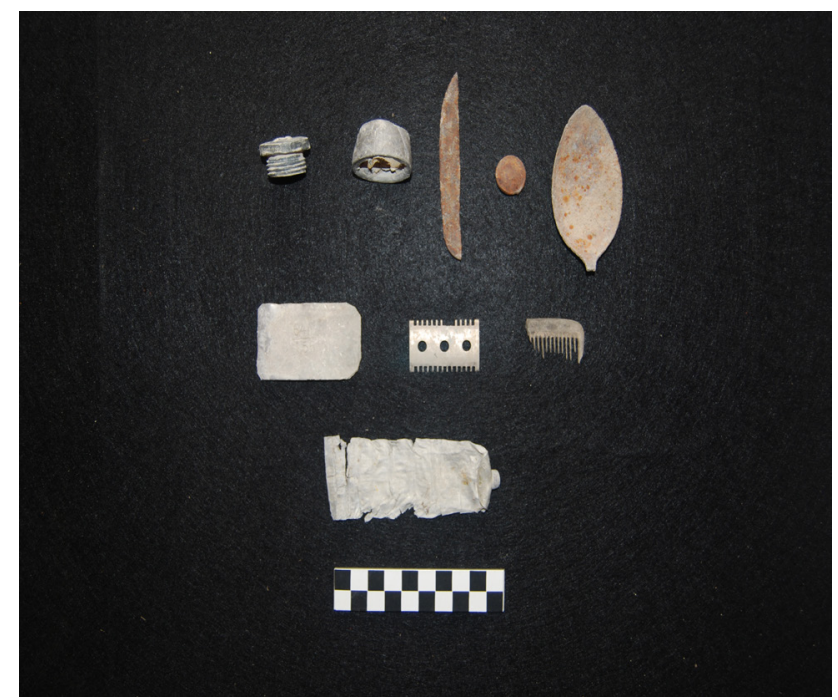

Fig. 4B: Ejemplo de material de uso cotidiano encontrado en prospección. Fotografía de los autores.

El siguiente punto donde localizamos este tipo de estructuras es el vértice Valdecantos, que se correspondería con la posición "Loma artillera" en su momento, donde junto a la red de trincheras y pozos de tirador se han conservado dos fortines de diferente tipología en mal estado de conservación. El primero de ellos de forma heptagonal, posiblemente fuera utilizado para su uso convencional, es 
decir albergar un arma automática, mientras que el segundo, de menores dimensiones posiblemente sirviese como observatorio. De esta zona se han recuperado un total de 118 piezas que incluyen únicamente cristal y metal. Entre ellos destaca un pequeño conjunto de latas de conserva y botellas de jerez y anís, así como varios peines de munición de fusil Máuser, varias vainas y fragmentos de metralla. La única intrusión en esta zona se corresponde con una vaina de carabina actual de calibre 22 mágnum.

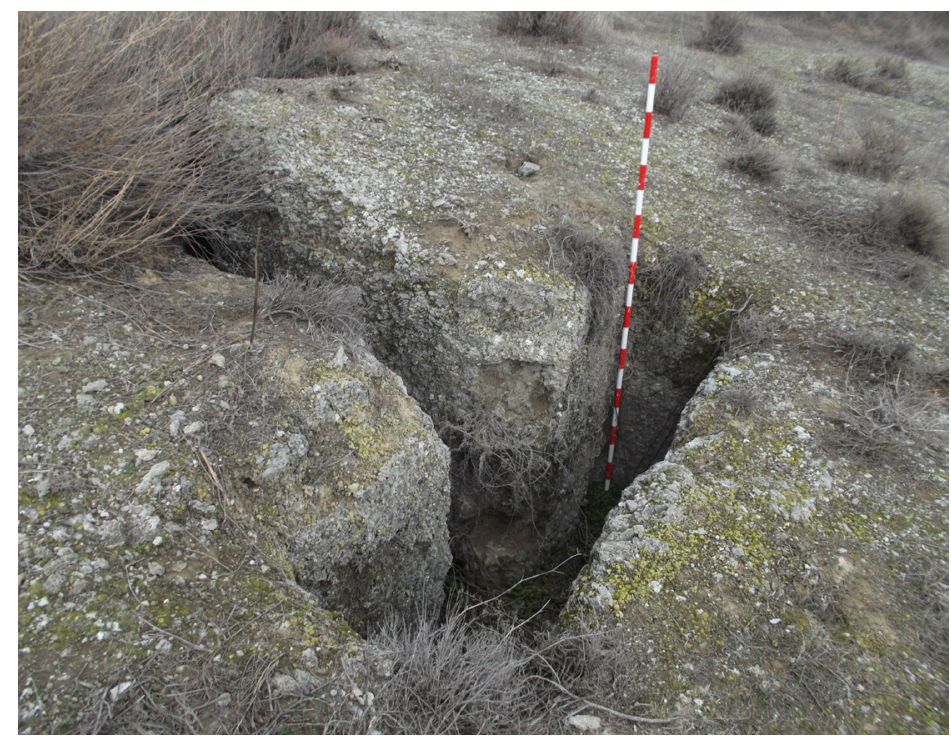

Fig. 5. Pozo de tirador doble en forma de "T" de la zona de "Los Yesares". Fotografía de los autores.

A su vez, en la zona de Valdecantos/Puerto de las dos caras, se localiza una posición de artillería fortificada mediante red de trincheras y la construcción de dos parapetos para fusilería "a barbeta" que guarnecen los extremos del lugar y tres estructuras para piezas de artillería que albergarían los cañones de la Batería. En su día estas estructuras eran cuatro, pero una de ellas ha desaparecido lo que coincide con el número de piezas que conforma una batería artillera, aspecto que ha sido corroborado mediante fotografía aérea antigua y con la documentación localizada en el Archivo General Militar de Ávila. En lo referente al material recuperado en la zona durante la prospección, hay que señalar que se trata de un conjunto escaso que sólo alcanza las 51 piezas. Se trata de piezas de metal y cristal que abarcan elementos constructivos y de fortificación entre los que destaca una piqueta de alambrada, y elementos relacionados con la vida cotidiana en el frente, como latas de conserva y restos de botellas. En cuanto al material bélico sólo se ha recuperado un cartucho de fusil sin disparar. 
Por último, en los parajes de Valdegrima y Valdeciervos se han localizado únicamente restos de estructuras negativas del tipo trincheras. Los materiales encontrados en la segunda zona se corresponden con un amplio conjunto de latas de conserva y material médico o veterinario. La tipología del material corroboraría el hecho de que fue una zona de paso debido al rápido avance de las tropas de caballería en dirección este durante la primera fase de la Batalla del Jarama, aunque este aspecto está en fase de investigación.

Es importante mencionar que todas las zonas documentadas tienen en común el estar fortificadas en todo su perímetro, lo que responde a los criterios de "fortificación de campaña" según los cuales se creaban "islotes de resistencia" independientes unos de otros pero con intervisibilidad y zonas batidas entre sí. Este modo de entender la fortificación huye de las grandes líneas de trinchera continua que requieren para su defensa gran número de efectivos, mientras que en este caso cada islote acoge a una unidad tipo compañía o inferior que se encarga de su defensa9.

Como es natural, el grado de conservación de las estructuras descritas anteriormente es diferente entre sí y entre las diferentes zonas, abarcando desde estructuras muy bien conservadas hasta las muy deterioradas, ya sea por efecto del paso del tiempo, la acción humana o como consecuencia de los combates acaecidos en la época.

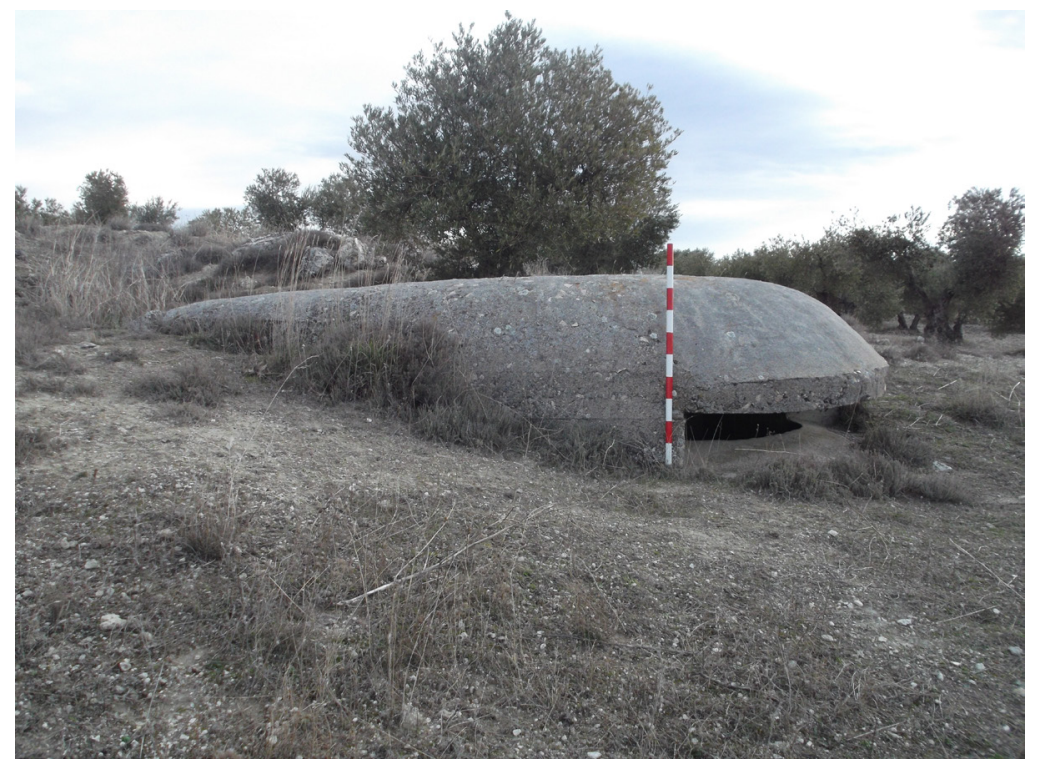

Fig. 6. Uno de los ocho fortines de la misma tipología localizados en Cabeza Fuete y Los yesares. Fotografía de los autores.

9 J.M. ARÉVALO: "La fortificación de campaña en la Guerra Civil Española". Revista de Historia Militar, 98 (2005), 181-221. 


\section{Conclusiones}

En los trabajos relacionados con la Arqueología de la Guerra Civil la metodología empleada no difiere de la que se utiliza en el estudio de otras épocas. La aplicación del método sólo se ve implementada por los datos que se obtienen de todas y de cada una de las fuentes consultadas, haciendo más completa la investigación si cabe. Este ha sido el caso de las posiciones localizadas en Pinto. Concretamente, el empleo de técnicas de prospección intensiva ha demostrado ser de gran utilidad a la hora de documentar campos de batalla. Estamos habituados a visualizar el lugar de una batalla cuando existen evidencias palpables, tales como estructuras de hormigón o trincheras bien conservadas. Pero no siempre podemos apreciar este tipo de restos y nuestra compresión del espacio disminuye. Por ello es de gran utilidad la información que nos aporta la prospección arqueológica, la recogida de materiales en superfice, su georreferenciación y posterior análisis en el gabinete, que nos permite delimitar espacios que de otro modo pasarían desapercibidos. Para ello recurrimos también al uso de fuentes historiográficas y bibliográficas, y como ya hemos señalado anteriormente, al uso de nuevas tecnologías que complementan la metodología tradicional. Nos referimos en concreto al empleo de la fotografía aérea y los sistemas de información geográfica, que combinados con los métodos tradicionales nos permiten llegar a delimitar espacios y relacionarlos con su entorno.

Por otro lado quisiéramos resaltar que la visión patrimonial de los restos de la Guerra Civil sigue estando bastante alejada de la sociedad española. Aun así, en los últimos años, van apareciendo nuevas iniciativas encaminadas a revalorizar los vestigios de la contienda, surgiendo con ello nuevos proyectos de investigación que enriquecen más si cabe la Arqueología del Conflicto. Pero todavía queda mucho camino por andar y mucha batalla por ganar.

\section{Bibliografía}

A. BEEVOR: La Guerra Civil Española. Círculo de Lectores, Barcelona: 2005,

A. PÉREZ: "Depresión del Tajo". En Gutiérrez Elorza, M. (ed.), Geomorfología de España. Rueda, Madrid: 1994, 389-436.

E. GONZÁLEZ PONS: "La Batalla de Madrid". Ejército revista ilustrada de las armas y servicios, 12 (1941), 35.

F. ALFÉREZ: "Estudio del sistema de terrazas del rio Tajo al oeste de Toledo". Estudios Geológicos, 33 (1977), 223-250.

J. GONZÁLEZ DE MIGUEL: "La defensa de Madrid". Desperta Ferro Contemporánea, 4 (2014), 28-39. 
J.M. ARÉVALO: "La fortificación de campaña en la Guerra Civil Española". Revista de Historia Militar, 98 (2005), 181-221.

J.M. GARCÍA RAMIREZ: La Batalla del Jarama Febrero 1937. Almena, Madrid: 2007.

R. CATELLANO: Los restos del asedio. Fortificaciones de la Guerra Civil en el Frente de Madrid Ejército Nacional. Almena, Madrid: 2004

R. LOZANO: "Museo Geominero" guía itinerario presentada en la Décima Semana de la Ciencia en Madrid. Instituto Geológico y minero, [en línea], Comunidad de Madrid, (2010). 